\title{
Progression of Left Ventricular Myocardial Dysfunction in Systemic Sclerosis: A Speckle-tracking Strain Echocardiography Study
}

\author{
Suzanne E. van Wijngaarden (D, Samira Ben Said-Bouyeri, Maarten K. Ninaber, \\ Tom W.J. Huizinga, Martin J. Schalij, Jeroen J. Bax, Victoria Delgado, \\ Jeska K. de Vries-Bouwstra, and Nina Ajmone Marsan
}

ABSTRACT. Objective. Cardiac involvement is a main cause of mortality in systemic sclerosis (SSc). Its detection remains challenging using conventional echocardiography and little is known about its potential progression. This study assessed changes in cardiac performance over time in a prospective cohort of patients with SSc, including echocardiographic speckle-tracking strain analysis.

Methods. The study included 234 patients with SSc [196 women, age $52 \pm 14$ yrs, 165 limited SSc, time since diagnosis 5.2 yrs, interquartile range (IQR) 2.9-11.3]. Clinical variables, laboratory tests, pulmonary function tests, and echocardiographic measures were recorded at baseline and followup (median 2.3 yrs, IQR 1.3-3.9). Additionally, left ventricular (LV) systolic function was assessed with global longitudinal strain (GLS) by echocardiographic speckle-tracking analysis.

Results. At followup, GLS had significantly worsened $(-21 \% \pm 2$ vs $-19 \% \pm 2, \mathrm{p}<0.001)$ while LV ejection fraction had not changed $(62 \% \pm 7$ vs $61 \% \pm 8, p=0.124)$. In particular, 39 patients showed a significant deterioration of GLS as defined by a $\geq 15 \%$ decrease, which was accompanied by a concomitant worsening of proximal muscle weakness, lung fibrosis, renal function, LV diastolic function, and right ventricular systolic function. Baseline variables associated with $\geq 15 \%$ deterioration in GLS were proximal muscle weakness (OR 3.437, 95\% CI 1.13-10.43, p = 0.020), decreased DLCO (OR 3.621, 95\% CI 1.25-10.51, p = 0.049), and LV diastolic dysfunction (OR 2.378, 95\% CI $1.07-5.27, \mathrm{p}=0.033)$.

Conclusion. In patients with SSc, progression of LV systolic dysfunction was demonstrated by GLS but not by LV ejection fraction. Proximal muscle weakness, DLCO, and LV diastolic dysfunction may identify patients at risk for progressive LV systolic dysfunction and in need of closer cardiac monitoring. (First Release March 1 2019; J Rheumatol 2019;46:405-15; doi:10.3899/jrheum.171207)

Key Indexing Terms:

SYSTEMIC SCLEROSIS

LEFT VENTRICULAR DYSFUNCTION

\section{MYOCARDIAL DISEASES 2-DIMENSIONAL ECHOCARDIOGRAPHY}

From the Department of Cardiology, Heart Lung Center, and the Department of Rheumatology, Leiden University Medical Center, Leiden, the Netherlands.

Supported by research grants from Biotronik, Edwards Lifesciences, Medtronic, and Boston Scientific, received by the Department of Cardiology.

S.E. van Wijngaarden, MD, MSc, Department of Cardiology, Leiden University Medical Center; S. Ben Said-Bouyeri, MD, MSc, Department of Rheumatology, Leiden University Medical Center; M.K. Ninaber, MD, PhD, Department of Cardiology, Heart Lung Centre, Leiden University Medical Center; T.W. Huizinga, MD, PhD, Department of Cardiology, Heart Lung Centre, Leiden University Medical Center; M.J. Schalij, MD, PhD, Department of Cardiology, Leiden University Medical Center; J.J. Bax, MD, PhD, Department of Cardiology, Leiden University Medical Center; V. Delgado, MD, PhD, Department of Cardiology, Leiden University Medical Center; J.K. de Vries-Bouwstra, MD, PhD, Department of Rheumatology, Leiden University Medical Center; N. Ajmone Marsan, $M D, P h D$, Department of Cardiology, Leiden University Medical Center.

Address correspondence to Dr.N. Ajmone Marsan, Department of

Cardiology, Leiden University Medical Center, Albinusdreef 2, 2333 ZA, P.O.

Box 9600, 2300 RC Leiden, the Netherlands.E-mail: N.ajmone@lumc.nl

Accepted for publication August 22, 2018.
Systemic sclerosis ( $\mathrm{SSc}$ ) is a connective tissue disease characterized by generalized microangiopathy and fibrosis affecting multiple organs, and is associated with increased mortality ${ }^{1}$. Primary cardiac involvement is common in SSc and can occur in up to $70 \%$ of patients as seen in autopsy reports ${ }^{2}$. Particularly, myocardial fibrosis may lead to diastolic and systolic dysfunction and to conduction abnormalities ${ }^{3,4,5}$. When clinically evident, cardiac involvement represents one of the main causes of death in patients with $\mathrm{SSc}^{6,7}$. Therefore, identification of myocardial involvement, ideally at a preclinical stage, is of crucial clinical importance for optimal patient management. To date, detection of myocardial dysfunction in patients with SSc has been challenging and no serial echocardiography studies have been performed to evaluate changes in cardiac performance over time. Conventional echocardiographic techniques lack sensitivity for early detection of left ventricular (LV) systolic

Personal non-commercial use only. The Journal of Rheumatology Copyright @ 2019. All rights reserved. 
dysfunction ${ }^{8,9}$. Yiu, et al demonstrated that novel echocardiographic speckle-tracking strain analysis may be a reliable tool to identify subtle myocardial dysfunction ${ }^{9}$. Particularly, a decrease in global longitudinal strain (GLS), as a marker of LV systolic dysfunction, was shown to be associated with lower functional capacity and the occurrence of arrhythmias. However, little is known about how LV systolic and diastolic dysfunction might progress over time and therefore how often, and in which patients, echocardiographic monitoring should be performed ${ }^{10}$.

The objective of our study was to assess changes over time in conventional and advanced echocardiographic parameters using sequential evaluations in a large, prospective cohort of patients with SSc. Additionally, we aimed to identify potential baseline clinical and echocardiographic characteristics associated with progressive LV systolic dysfunction, to help clinicians select patients at risk of myocardial involvement who deserve close followup.

\section{MATERIALS AND METHODS}

Patient population. Starting in 2009, consecutive patients with SSc visiting the Department of Rheumatology of the Leiden University Medical Center (Leiden, The Netherlands) were evaluated in a specifically designed healthcare program combining annual organ screening with multidisciplinary team care (The Leiden Systemic Sclerosis Cohort) ${ }^{11,12}$. For our study, patients with at least 2 echocardiographic evaluations were included. Exclusion criteria for the current evaluation were previous myocardial infarction, presence of cardiomyopathy of other causes, and moderate to severe valve stenosis or regurgitation. A baseline echocardiography was selected corresponding to the date of the first visit to the care program. The followup echocardiography was defined as the last one available with a minimum of 1 year after the baseline examination. Patients were diagnosed according to the classification system described by LeRoy and Medsger ${ }^{13}$. Patient written consent and approval by the medical ethics committee was obtained (REU 043).

Clinical variables. Disease-related characteristics were reported at baseline and followup visits, including modified Rodnan skin score (mRSS), SSc subtype (diffuse or limited), proximal muscle strength, and arthritis. Laboratory testing included renal function, $\mathrm{N}$-terminal pro-brain natriuretic peptide (NT-proBNP), C-reactive protein (CRP), erythrocyte sedimentation rate (ESR), and creatine phosphokinase (CPK). These measures were categorized as elevated or not according to local reference values. To assess functional capacity, 6-min walking distance tests were performed. Pulmonary involvement was assessed by performing spirometry tests according to the recommendations and included percentage of predicted values for forced vital capacity (FVC), forced expiratory volume in 1 second (FEV1), and DLCO. These were categorized as impaired or not according to reference values ${ }^{14,15}$. Presence of lung fibrosis was determined from abnormal findings on thoracic high-resolution computed tomography ${ }^{16,17}$. Patients underwent cardiopulmonary exercise tests on an electrically ramped cycle ergometer according to these guidelines ${ }^{18}$ : the peak oxygen consumption $(\mathrm{VO} 2 \max \%)$ was measured and values $<80 \%$ of predicted were categorized as decreased. An mRSS increase of $\geq 5$ or FVC and DLCO decrease of $\geq 10 \%$ were considered increased disease activity ${ }^{19}$. Each patient had a 24-h Holter electrocardiogram (ECG) at baseline. Presence of conduction defects and ventricular and supraventricular arrhythmias was recorded ${ }^{20,21}$

All-cause mortality data were obtained by retrieval of survival status through the municipal civil registries. Time till death was calculated from date of followup echo until date of death.
Conventional echocardiography. All patients underwent echocardiography in the left lateral decubitus position, using a commercially available system (Vivid 7 and E9; General Electric) and 3.5-MHz or 5 MS transducers. Standard M-mode and 2-dimensional, color, pulsed, and continuous wave Doppler images were acquired. Offline analysis was performed using EchoPAC (version 112.0.1; GE Medical Systems).

LV end-diastolic diameter (LVEDd) and volume (LVEDV), end-systolic volume (LVESV) and ejection fraction (EF), and left atrial diameter (LAD) were measured according to current guidelines ${ }^{22}$. LV diastolic function was assessed using a multiparametric approach including (1) peak early (E) and late (A) diastolic velocities and E-wave deceleration time measured on pulsed-wave Doppler recordings of the transmitral flow, (2) E/A ratio, and (3) E-prime measured with tissue Doppler imaging at the lateral side of the mitral annulus in the apical 4-chamber view ${ }^{23}$. According to current guidelines, impaired LV relaxation was defined based on an E-prime value $\leq 10$ $\mathrm{cm} / \mathrm{sec}^{23}$.

Pulmonary arterial systolic pressure (sPAP) was estimated by determining right ventricular systolic pressure, calculated from the tricuspid regurgitation peak gradient, and adding the right atrial pressure estimated by the inferior vena cava diameter and degree of respiratory collapse. Elevated sPAP was defined as $>35 \mathrm{mmHg}^{24}$. Right ventricular systolic function was assessed by the tricuspid annular plane systolic excursion (TAPSE) on M-mode recordings of the tricuspid annulus ${ }^{25}$. Presence of pericardial effusion was also recorded.

Two-dimensional speckle-tracking echocardiographic (STE) strain analysis. Two-dimensional STE analysis is an echocardiographic technique that quantifies myocardial deformation (strain) by tracking myocardial acoustic markers (speckles) in every frame within 1 cardiac cycle ${ }^{22}$. LV strain was measured in the longitudinal direction using 3 standard apical views (Figure 1). Each wall is divided into basal, middle, and apical segments and 18 segmental curves were obtained. GLS is automatically calculated as the average value of the peak systolic strain ${ }^{22}$ (Figure 1). Reflecting the shortening of LV myocardium, GLS is expressed as negative values and a more negative value represents better myocardial deformation.

Statistical analyses. Data analyses were performed using SPSS software 23.0 (IBM). Continuous variables are presented as mean \pm SD or median with interquartile ranges (IQR) according to normal distribution. Categorical data are presented as frequencies and percentages. Continuous variables were compared using 1-way ANOVA, applying the Bonferroni posthoc analysis, or the Kruskal-Wallis 1-way ANOVA. Categorical variables were compared with chi-square tests. Changes over time were compared with linear mixed model analysis with unstructured covariance matrix, Wilcoxon signed-rank test for continuous variables, and generalized linear models with binary logistic response for comparing changes in categorical variables between 2 groups. To compare baseline characteristics between groups, $\geq 15 \%$ GLS reduction and followup time were incorporated into the models. A GLS reduction of $\geq 15 \%$ was chosen arbitrarily because it most likely reflects clinical decline as opposed to minor deviations ${ }^{26}$. Logistic regression analyses were performed to identify baseline variables associated with $\geq$ $15 \%$ GLS reduction at followup. Extracardiac variables significant in the univariate analyses were included in a multivariate baseline model. Limited by the number of events ( $\geq 15 \%$ GLS reduction), the clinically most relevant parameters were chosen. Cardiac variables significant in the univariate analyses were added separately to the multivariate baseline model. A univariate Cox regression analysis and a log-rank test were performed to assess the association of $\geq 15 \%$ reduction of GLS and all-cause mortality. A $\mathrm{p}$ value $<0.05$ was considered statistically significant.

\section{RESULTS}

Patient characteristics. Table 1 summarizes the baseline characteristics of the 234 patients with SSc, 165 (70\%) of them having limited cutaneous SSc and 69 (30\%) having diffuse cutaneous SSc. Ninety-two percent fulfilled American 


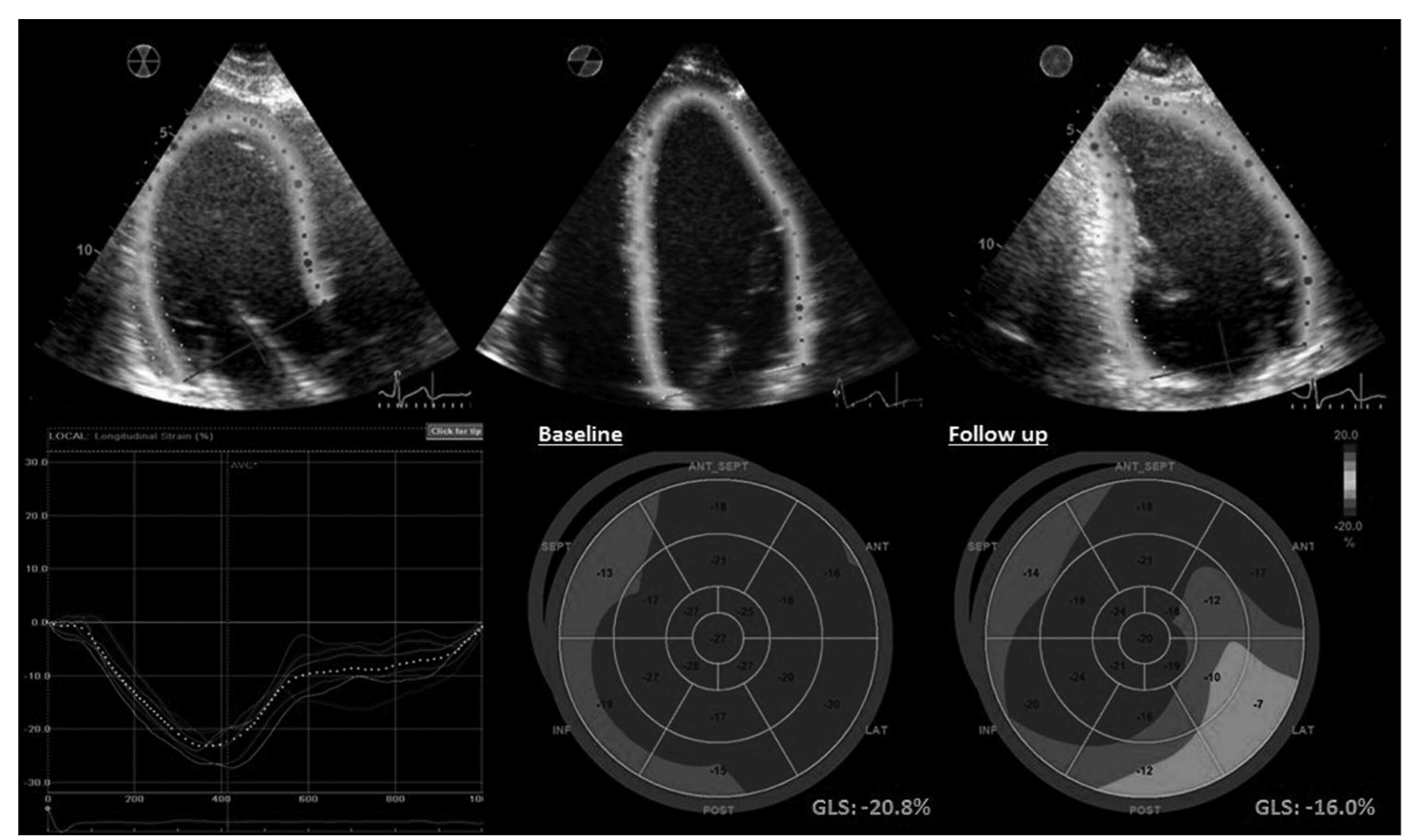

Figure 1. GLS of the left ventricle measured by 2-dimensional speckle-tracking strain analysis applied to 3-chamber (top left), 4-chamber (top middle), and 2-chamber apical views (top right). Bottom left: curves of longitudinal strain per segment and averaged among the segments (dotted line). Bottom middle: bull's-eye display of segmental peak systolic longitudinal strain values at baseline of a patient with SSc; darkest grey representing preserved strain and lighter grey impaired strain. Bottom right: bull's-eye display at followup of the same patient; lightest color indicates even worse contractility (more impaired). GLS is calculated averaging the 17 segments. GLS: global longitudinal strain; SSc: systemic sclerosis.

College of Rheumatology (ACR) 2013 criteria $^{27}$. Patients had a mean age of $52 \pm 14$ years, and 196 patients $(84 \%)$ were women. The median time since diagnosis was 5.2 years (IQR 2.9-11.3). Median time since onset of Raynaud symptoms was 9.8 years (IQR 4.5-19.0) and median time since first non-Raynaud manifestation was 4.8 years (IQR 1.9-10.6). The median period between baseline and followup echocardiography was 2.3 years (IQR 1.3-3.9).

Clinical variables at baseline versus followup evaluation. No significant changes in median mRSS scores were observed at followup; however, the number of patients with mRSS $>15$ was reduced at followup (Table 1), and mRSS increased by $\geq 5$ in 30 patients $(13 \%)$. No changes were observed in the presence of arthritis, muscle weakness, 6-min walking distance, laboratory markers (Appendix 1), decreased FEV1, FVC, or DLCO. FVC and DLCO decreased by $\geq 10 \%$ in 45 (19\%) and 46 (20\%) patients, respectively. Prevalence of lung fibrosis, renal function impairment (defined as estimated glomerular filtration rate $<60 \mathrm{ml} / \mathrm{min} / 1.73 \mathrm{~m}^{2}$ ), and impaired $\mathrm{VO} 2 \mathrm{max} \%$ increased significantly over time.

Echocardiographic variables. Although LVEDV slightly decreased at followup, no other changes were detected in LVESV and subsequently in LVEF (Table 1). In addition, LAD increased slightly over time. A relative worsening of LV diastolic function was observed as reflected by a reduction of the E/A ratio and a significant increase in percentage of patients with lateral E-prime $\leq 10 \mathrm{~cm} / \mathrm{sec}$ (defining LV diastolic dysfunction). Interestingly, $13 \%$ of the population had lateral E-prime $\leq 10 \mathrm{~cm} / \mathrm{sec}$ de novo at followup. Further, sPAP slightly increased over time, which is also reflected in a significant increase of the proportion of patients having elevated sPAP (from 9\% to $12 \%, \mathrm{p}<0.001$ ) defined as SPAP $>35 \mathrm{mmHg}$. New development of elevated sPAP was observed in $6 \%$ of the patients. Further, there was a decline in right ventricular function over time as reflected by a decrease in TAPSE. Occurrence of pericardial effusion increased and new onset at followup was observed in 5\% of patients.

Decrease in LV systolic function as assessed by GLS and its clinical and echocardiographic associates. Compared to baseline, GLS significantly decreased at followup (Table 1). Particularly, 39 patients (19\%) showed a significant decrease in LV systolic function as defined by GLS reduction of $\geq 15 \%$ $(-20.9 \% \pm 2.0$ to $-16.3 \% \pm 2.4, \mathrm{p}<0.001)$, while 165 patients $(81 \%)$ showed less or no decline in GLS $(-21.0 \% \pm 1.9$ to $-20.0 \% \pm 1.9, \mathrm{p}<0.001)$. The followup period was slightly longer in patients with GLS reduction [median $3.08 \mathrm{yrs}$ (IQR $1.92-4.17$ ) vs 2.25 yrs (IQR $1.17-3.83, \mathrm{p}=0.048$ ].

A comparison of baseline extracardiac variables between patients with or without significant GLS reduction is shown in Table 2. There were no differences in age, sex, or time since Raynaud or non-Raynaud manifestations between the 2 groups. No significant difference in SSc type was found, although the percentage of diffuse cutaneous SSc was slightly

Personal non-commercial use only. The Journal of Rheumatology Copyright @ 2019 . All rights reserved. 
Table 1. Clinical characteristics and echocardiographic variables at baseline and followup in the total patient population.

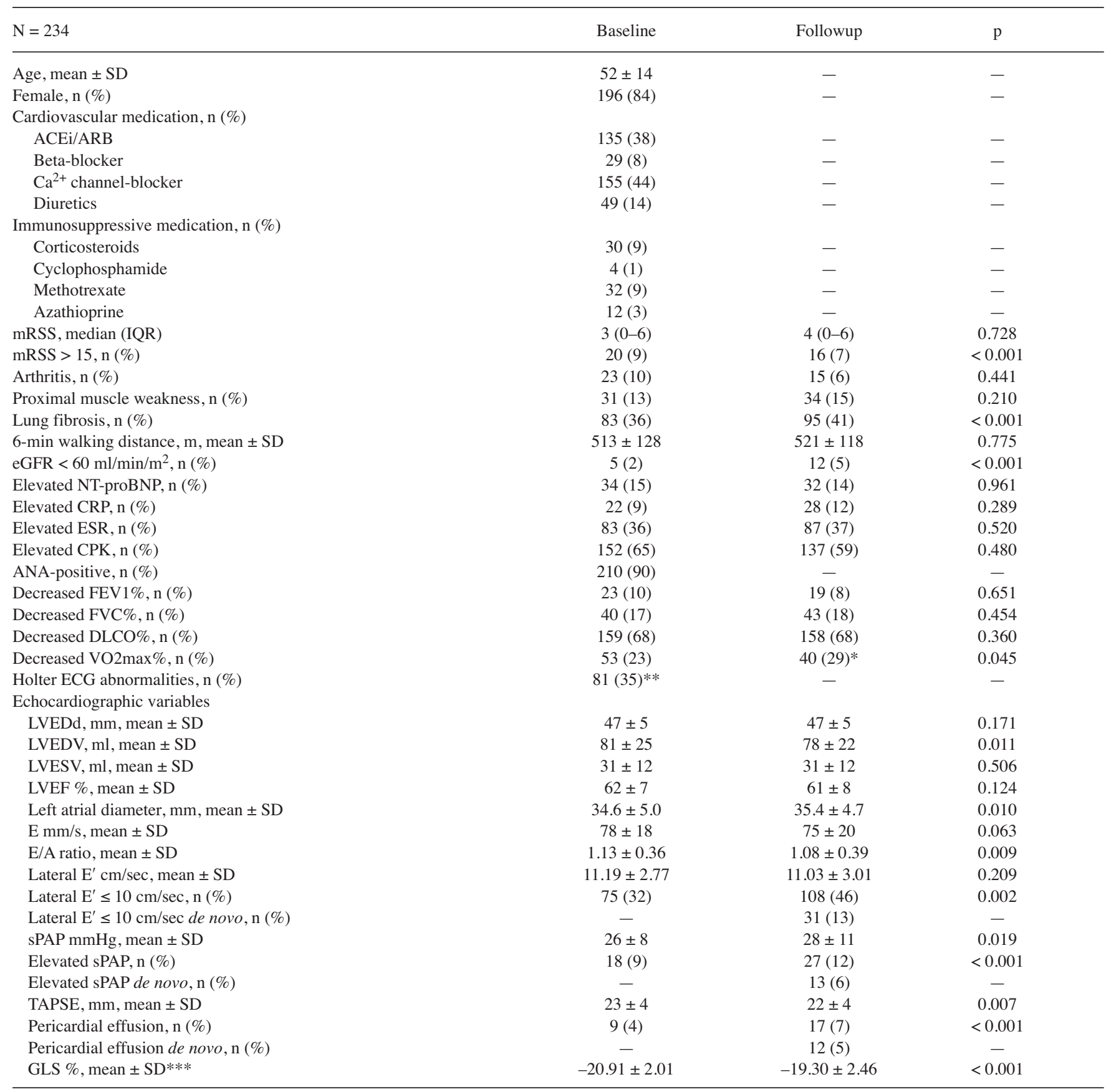

* 98 patients with missing data. ** 8 patients with missing data. *** Speckle-tracking strain feasible in both baseline and followup echocardiogram in 204 patients. ACEi: angiotensin-converting enzyme inhibitor; ANA: antinuclear antibodies; ARB: angiotensin II receptor blocker; CPK: creatine phosphokinase, cutoff value $145 \mathrm{U} / \mathrm{l}$; CRP: C-reactive protein, cutoff value $10 \mathrm{mg} / \mathrm{l}$; E/A: peak early (E) and late (A) diastolic velocities; ECG: electrocardiogram; eGFR: estimated glomerular filtration rate; ESR: erythrocyte sedimentation rate, cutoff value $20 \mathrm{~mm}$; FEV1: forced expiratory volume in $1 \mathrm{~s}$, percent of predicted value, cutoff value $70 \%$; FVC: forced vital capacity, percent of predicted value, cutoff value $80 \%$; GLS: global longitudinal strain; LV: left ventricular; LVEDd: LV end-diastolic diameter; LVEDV: LV end-diastolic volume; LVESV: LV end-systolic volume; LVEF: LV ejection fraction; mRSS: modified Rodnan skin score; NT-proBNP: N-terminal pro-brain natriuretic peptide, cutoff value $300 \mathrm{ng} / \mathrm{l}$; sPAP: systolic pulmonary arterial pressure; TAPSE: tricuspid annular plane systolic excursion; $\mathrm{VO} 2$ max: maximum $\mathrm{O}_{2}$ uptake during exercise, percent of predicted value, cutoff value $80 \%$; IQR: interquartile range.

higher among patients with GLS reduction of $\geq 15 \%(36 \%$ vs $27 \%$ in their counterparts, $\mathrm{p}=0.25)$. The percentage of patients positive for antinuclear antibodies was similar in both groups ( $87 \%$ vs $92 \%, \mathrm{p}=0.987)$. Presence of myositis was similar [3 $(2 \%)$ vs $2(5 \%), p=0.206]$. Clinical variables including mRSS and arthritis were not significantly different 
Table 2. Comparison of baseline clinical variables between patients with $\geq 15 \%$ decrease of GLS versus $<15 \%$ decrease at followup.

\begin{tabular}{|c|c|c|c|}
\hline $\mathrm{N}=204$ & $<15 \%$ Decrease GLS, $\mathrm{n}=165$ & $\geq 15 \%$ Decrease GLS, $\mathrm{n}=39$ & $\mathrm{p}$ \\
\hline Age, mean $\pm \mathrm{SD}$ & $52 \pm 13$ & $55 \pm 14$ & 0.236 \\
\hline Female, $\mathrm{n}(\%)$ & $139(84)$ & $31(80)$ & 0.474 \\
\hline Time since non-Raynaud symptoms, yrs, median (IQR) & $4(2-10)$ & $5(1-10)$ & 0.999 \\
\hline \multicolumn{4}{|l|}{ Cardiovascular medication, $\mathrm{n}(\%)$} \\
\hline $\mathrm{ACEi} / \mathrm{ARB}$ & $56(34)$ & $18(46)$ & 0.083 \\
\hline Diuretics & $16(10)$ & $4(10)$ & 0.824 \\
\hline \multicolumn{4}{|l|}{ Immunosuppressive medication, $\mathrm{n}(\%)$} \\
\hline Corticosteroids & $17(10)$ & $9(23)$ & 0.020 \\
\hline Cyclophosphamide & $2(1)$ & $2(5)$ & 0.096 \\
\hline Methotrexate & $21(13)$ & $8(21)$ & 0.155 \\
\hline Azathioprine & $10(6)$ & $3(8)$ & 0.126 \\
\hline Lung fibrosis, $\mathrm{n}(\%)$ & $58(35)$ & $17(44)$ & 0.326 \\
\hline 6 -min walking distance, $\mathrm{m}$, mean $\pm \mathrm{SD}$ & $517 \pm 127$ & $515 \pm 132$ & 0.966 \\
\hline $\mathrm{eGFR}<60 \mathrm{ml} / \mathrm{min} / \mathrm{m}^{2}, \mathrm{n}(\%)$ & $2(1)$ & $2(5)$ & 0.113 \\
\hline Elevated NT-proBNP, n (\%) & $18(11)$ & $12(31)$ & 0.001 \\
\hline Elevated CRP, n (\%) & $16(10)$ & $4(10)$ & 0.916 \\
\hline Elevated ESR, n (\%) & $59(36)$ & $16(41)$ & 0.612 \\
\hline Elevated CPK, n (\%) & $104(63)$ & $29(74)$ & 0.182 \\
\hline ANA-positive, n (\%) & $151(92)$ & $34(87)$ & 0.987 \\
\hline Decreased FEV1\%, n (\%) & $14(9)$ & $5(13)$ & 0.409 \\
\hline Decreased FVC\%, n (\%) & $20(12)$ & $10(26)$ & 0.035 \\
\hline Decreased DLCO $\%$, n (\%) & $106(64)$ & $34(87)$ & 0.009 \\
\hline Decreased VO2max $\%, \mathrm{n}(\%)$ & $57(35)$ & $16(41)$ & 0.017 \\
\hline
\end{tabular}

ACEi: angiotensin-converting enzyme inhibitor; ANA: antinuclear antibodies; ARB: angiotensin II receptor blocker; CPK: creatine phosphokinase, cutoff value 145 U/1; CRP: C-reactive protein, cutoff value $10 \mathrm{mg} / 1$; ECG: electrocardiogram; eGFR: estimated glomerular filtration rate; ESR: erythrocyte sedimentation rate, cutoff value $20 \mathrm{~mm}$; FEV1: forced expiratory volume in $1 \mathrm{~s}$, percent of predicted value, cutoff value 70\%; FVC: forced vital capacity, percent of predicted value, cutoff value $80 \%$; GLS: global longitudinal strain; mRSS: modified Rodnan skin score; NT-proBNP: N-terminal pro-brain natriuretic peptide, cutoff value $300 \mathrm{ng} / \mathrm{l}$; VO2max: maximum $\mathrm{O}_{2}$ uptake during exercise, percent of predicted value, cutoff value $80 \%$; IQR: interquartile range.

between the groups, although they were numerically worse among patients with GLS reduction. Patients with GLS reduction had a significantly higher frequency of muscle weakness compared to patients without GLS reduction. Additionally, elevated NT-proBNP, decreased FVC, DLCO, and $\mathrm{VO} 2 \mathrm{max} \%$ were significantly more prevalent in patients with significant GLS reduction. No differences were observed in the prevalence of elevated CRP, ESR, CPK, and Holter-ECG abnormalities at baseline, although the latter occurred numerically more often in patients with GLS reduction.

Over time, in patients with GLS reduction, various concomitant increases were observed: of proximal muscle weakness, lung fibrosis, and impairment of renal function, in comparison to their counterparts (Figure 2A). Additionally, mRSS increase $\geq 5$ and FVC decrease $\geq 10 \%$ occurred significantly more often (Figure 2B) in patients with GLS reduction and DLCO decrease $\geq 10 \%$ showed a trend toward a higher prevalence in this group $(28 \%$ vs $19 \%, \mathrm{p}=0.191)$.
Echocardiographic variables. As for LA and LV dimensions, volumes, and systolic function, no differences were seen at baseline between the 2 groups (Table 3 ). However, patients with GLS reduction had a significantly lower E/A ratio and lateral E-prime and a higher prevalence of lateral E-prime $\leq 10 \mathrm{~cm} / \mathrm{sec}$, suggesting worse LV diastolic function compared to those with less reduction of GLS. At baseline, the GLS reduction group also had a significantly higher sPAP and a worse right ventricular function reflected by a lower TAPSE.

Over time, no significant changes were seen in LVEF in patients with and without GLS reduction ( $\mathrm{p}=0.066$ and $\mathrm{p}=$ 0.246 ), although the $p$ value was almost significant in patients with GLS reduction. Patients with GLS reduction showed a significant deterioration in E-prime $(10.2 \pm 2.5 \mathrm{~cm} / \mathrm{sec}$ to 9.1 $\pm 2.6 \mathrm{~cm} / \mathrm{sec}, \mathrm{p}=0.014)$ and TAPSE ( $22 \pm 4$ to $20 \pm 4 \mathrm{~mm}$, $\mathrm{p}=0.003)$ in contrast to their counterparts $(\mathrm{p}=0.564$ and $\mathrm{p}=0.150$, respectively). Moreover, patients classified as having LV diastolic dysfunction increased significantly in

Personal non-commercial use only. The Journal of Rheumatology Copyright $\subset$ 2019. All rights reserved. 

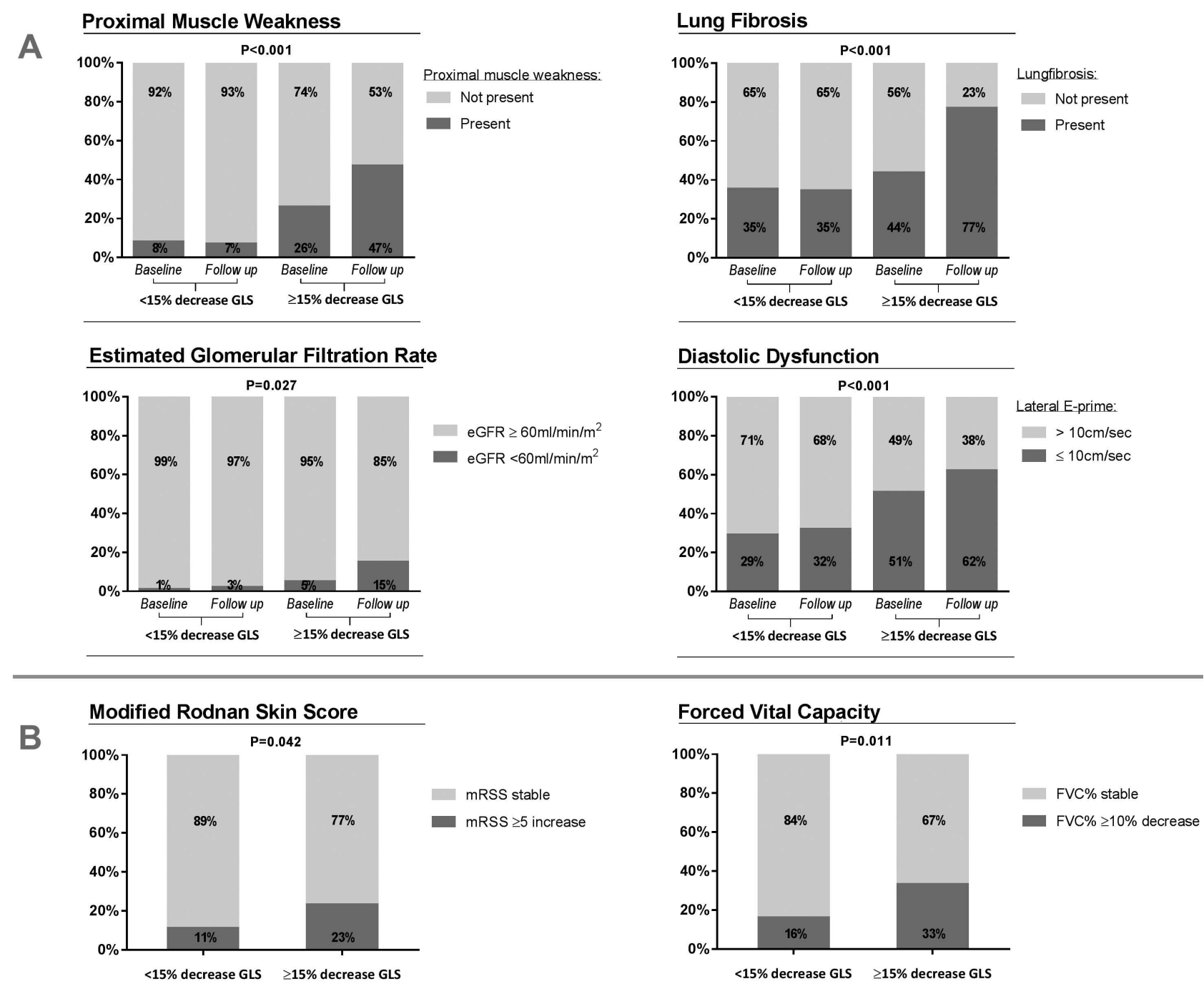

Figure 2. A. Baseline and followup prevalence of clinical variables and lateral E-prime $\leq 10 \mathrm{~cm} / \mathrm{sec}$ (a marker for left ventricular diastolic dysfunction) compared between patients with $\geq 15 \%$ decrease of GLS versus $<15 \%$ decrease. B. Prevalence of clinical variables at followup considered as signs of increased disease activity compared between the latter 2 groups. GLS: global longitudinal strain; eGFR: estimated glomerular filtration rate; mRSS: modified Rodnan skin score; FVC: forced vital capacity.

patients with GLS reduction (Figure 2A). Over time, sPAP did not change significantly in both groups. However, more patients developed elevated SPAP at followup among those with GLS reduction ( $6 \%$ vs $2 \%, \mathrm{p}<0.001)$. Patients with GLS reduction were at increased risk for developing elevated sPAP at followup (OR 2.575, 95\% CI 0.999-6.635, $\mathrm{p}=0.050)$.

The prevalence of pericardial effusion increased similarly in both groups (3\% to $8 \%, \mathrm{p}=0.077$, and $4 \%$ to $7 \%$, $\mathrm{p}<0.001$, respectively).

Univariate and multivariate analyses to identify associates of GLS reduction at followup. According to logistic regression analyses (Table 4), baseline extracardiac variables significantly associated with GLS reduction were use of corticosteroids, proximal muscle weakness, elevated NT-proBNP, decreased FVC, DLCO, and VO2max\%. Cardiac variables significantly associated with GLS reduction were E/A ratio, lateral E-prime, lateral E-prime $\leq 10 \mathrm{~cm} / \mathrm{s}, \mathrm{sPAP}$, elevated sPAP, and TAPSE. Indicated by the number of patients with GLS reduction (39 patients), first a baseline model was created for multivariate analysis that included 4 extracardiac variables that were significant in the univariate analysis (corticosteroid use, proximal muscle weakness, decreased DLCO, and elevated NT-proBNP). In the baseline model, proximal muscle weakness and decreased DLCO remained independently associated with GLS reduction. Together with elevated NT-proBNP, these variables were used as a baseline model for further multivariate analyses. When lateral E-prime $\leq 10 \mathrm{~cm} / \mathrm{sec}$ was added to the model, proximal muscle weakness, decreased DLCO, and lateral E-prime $\leq 10 \mathrm{~cm} / \mathrm{sec}$ 
Table 3. Comparison of baseline echocardiographic measures between patients with $\geq 15 \%$ decrease of GLS versus $<15 \%$ decrease at followup.

\begin{tabular}{|c|c|c|c|}
\hline$N=204$ & $<15 \%$ Decrease GLS, $\mathrm{n}=165$ & $\geq 15 \%$ Decrease GLS, $\mathrm{n}=39$ & $\mathrm{p}$ \\
\hline LVEDd $m m$, mean \pm SD & $47 \pm 5$ & $47 \pm 7$ & 0.719 \\
\hline LVEDV ml, mean \pm SD & $81 \pm 24$ & $80 \pm 24$ & 0.795 \\
\hline $\mathrm{LVEF} \%$, mean $\pm \mathrm{SD}$ & $62 \pm 7$ & $60 \pm 8$ & 0.106 \\
\hline Left atrial diameter mm, mean $\pm \mathrm{SD}$ & $36 \pm 6$ & $35 \pm 5$ & 0.093 \\
\hline $\mathrm{E} \mathrm{mm} / \mathrm{s}$, mean $\pm \mathrm{SD}$ & $77 \pm 17$ & $77 \pm 21$ & 0.114 \\
\hline Lateral $\mathrm{E}^{\prime} \leq 10 \mathrm{~cm} / \mathrm{s}, \mathrm{n}(\%)$ & $45(27)$ & $20(51)$ & 0.005 \\
\hline $\mathrm{sPAP} m m H g$, mean $\pm \mathrm{SD}$ & $25 \pm 8$ & $30 \pm 8$ & 0.004 \\
\hline Elevated sPAP, n (\%) & $10(6)$ & $6(15)$ & 0.036 \\
\hline TAPSE mm, mean \pm SD & $23 \pm 4$ & $22 \pm 4$ & 0.031 \\
\hline Pericardial effusion, n (\%) & $7(4)$ & $1(3)$ & 0.627 \\
\hline
\end{tabular}

GLS: global longitudinal strain; LV: left ventricular; LVEDd: LV end-diastolic diameter; LVEDV: LV end-diastolic volume; LVESV: LV end-systolic volume; LVEF: LV ejection fraction; E/A: peak early (E) and late (A) diastolic velocities; sPAP: systolic pulmonary arterial pressure; TAPSE: tricuspid annular plane systolic excursion.

remained independently associated with GLS reduction. When elevated SPAP was added to the baseline model, proximal muscle weakness and decreased DLCO remained significant. When TAPSE was added to the baseline model, proximal muscle weakness and decreased DLCO remained independently associated with GLS reduction.

All-cause mortality occurred in 25 patients. Significantly more patients with GLS reduction died [9 (23.1\%) vs 11 $(7 \%), p=0.002$, respectively]. GLS reduction was associated with increased risk of all-cause mortality (HR 2.771, 95\% CI $1.002-7.666, \mathrm{p}=0.050 ;$ log-rank 4.330, $\mathrm{p}=0.037$ ).

\section{DISCUSSION}

Our study is the first, to our knowledge, to assess serial echocardiography in a relatively large group of patients with SSc reflecting the whole spectrum of disease severity. Our study showed that advanced STE can detect a decline in LV systolic function over a relatively short period of time. A reduction of $\geq 15 \%$ in GLS was found in $19 \%$ of the patients at followup. Patients with $\geq 15 \%$ GLS reduction were more likely to have proximal muscle weakness, lung fibrosis, renal impairment, and elevated NT-proBNP at followup. Additionally, $\geq 15 \%$ GLS reduction was associated with all-cause mortality.

Identified as independent associates of $\geq 15 \%$ GLS reduction at followup were proximal muscle weakness, decreased DLCO, and lateral E-prime $\leq 10 \mathrm{~cm} / \mathrm{sec}$ (as a marker of LV diastolic dysfunction) at baseline. Studies in large SSc patient populations demonstrated that cardiac involvement is the most or the second-most prevalent cause of mortality ${ }^{6,7}$. However, identification of cardiac involvement remains challenging and recommendations are usually based on clinical symptoms or conventional echocardiography. Cardiac involvement is frequently described as presence of arrhythmias and/or LV dysfunction, and/or pericardial effusion ${ }^{9,28,29,30}$. Particularly, LV diastolic dysfunction is often observed in patients with SSc, even at young ages ${ }^{28,29,30}$. In turn, impaired LV systolic function, as measured by LVEF, is not frequently observed in patients with SSc, mainly owing to the low sensitivity for detecting subtle myocardial systolic dysfunction ${ }^{8}$. One study demonstrated that advanced echocardiographic strain analysis is more sensitive for detecting LV systolic dysfunction ${ }^{9}$, which is more prevalent than initially described and is associated with reduced functional capacity and DLCO. However, little is known about when LV systolic dysfunction may occur or whether it may progress, because we lack sequential echocardiographic studies.

Our current study offers a unique description of the typical course of the disease, because it is the first, to our knowledge, to assess changes in SSc-related clinical and echocardiographic characteristics over time. Although conventional echocardiography could assess a relative progression in LV diastolic dysfunction and a mild impairment in right ventricular systolic function, LVEF did not change over time. When using GLS as a more sensitive marker of LV systolic function, progressive impairment in LV systolic function could be detected, which was substantial in almost $20 \%$ of the cases. Interestingly, next to increases of proximal muscle weakness, lung fibrosis, renal dysfunction, and elevated NT-proBNP, clinical deterioration of mRSS and FVC were more frequent in patients with GLS reduction. These findings suggest that STE echocardiography can detect subtle changes in LV systolic myocardial function and may reflect disease activity and cardiac involvement, and is significantly associated with all-cause mortality. It may therefore be a useful tool in a preclinical stage and thus contribute to risk stratification in SSc.

Potential associates to LV systolic dysfunction. Manifestation of proximal muscle weakness, potentially reflecting

Personal non-commercial use only. The Journal of Rheumatology Copyright $\odot$ 2019. All rights reserved. 


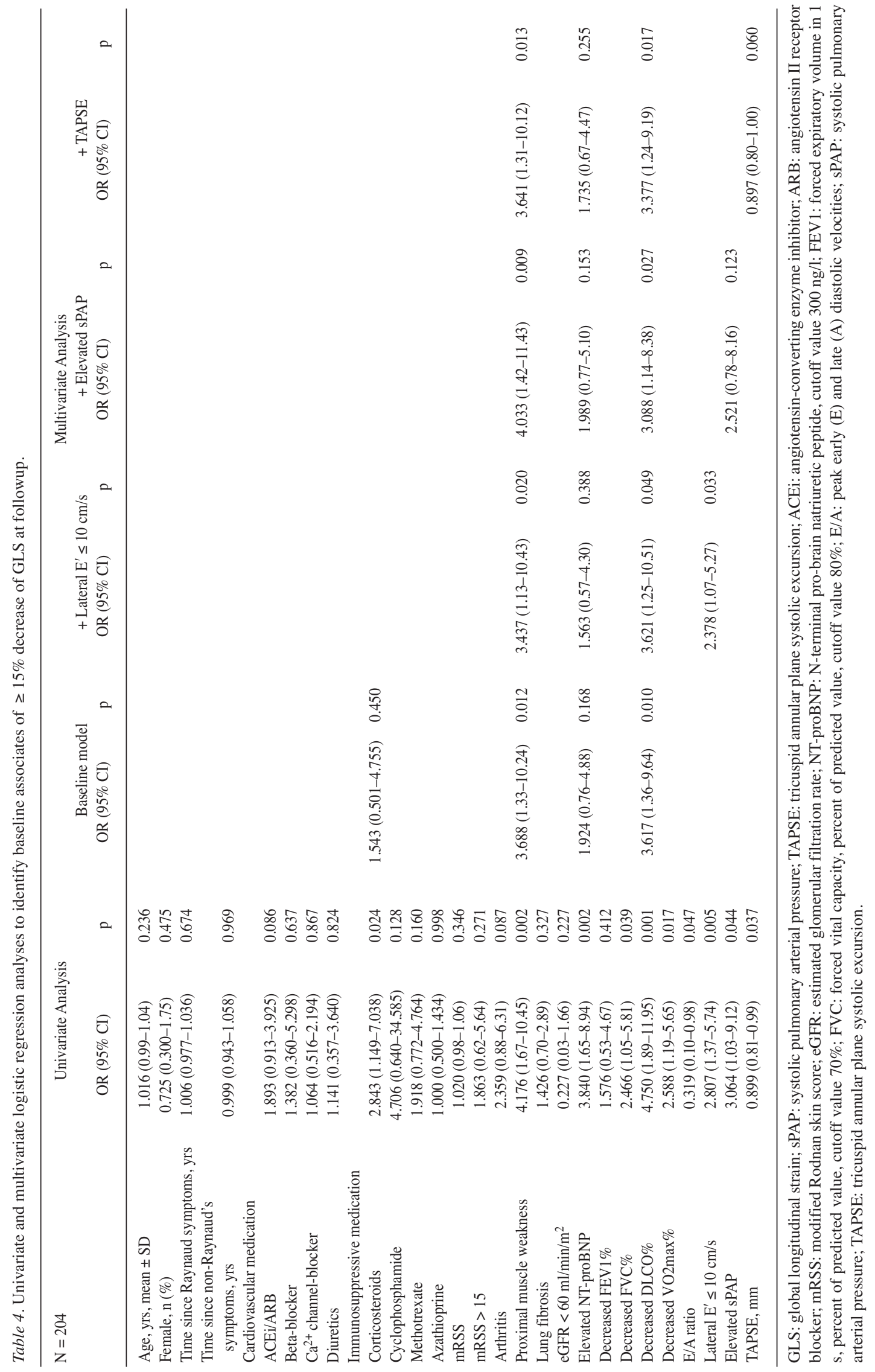

Personal non-commercial use only. The Journal of Rheumatology Copyright @ 2019 . All rights reserved. 
involvement of the skeletal muscles, has been associated with increased risk of myocardial involvement such as congestive heart failure, myositis, arrhythmias, or conduction defects $^{31,32,33,34}$. Allanore and colleagues reported proximal muscle weakness to be independently associated with a decreased LV systolic function, which occurred in $5.4 \%$ of the population ${ }^{8}$. Additionally, the current study emphasizes the clinical importance of detecting proximal muscle weakness for identifying patients at high risk of developing LV dysfunction.

Impaired DLCO is also known to be associated with reduced functional capacity and as a predictor of interstitial lung disease $\mathrm{s}^{35,36,37}$. Therefore, as our current study suggests, decreased DLCO may indicate both primary and secondary (to pulmonary involvement) cardiac involvement, and may be considered as a marker of potential progression in $\mathrm{LV}$ systolic dysfunction over time.

Although elevated NT-proBNP was more prevalent in patients with GLS reduction, no significant association was found. This may be because NT-proBNP is elevated by more overt LV dysfunction and also reflects noncardiac abnormalities (e.g., renal dysfunction).

In addition, the presence of LV diastolic dysfunction has been shown to be associated with disease duration and an increased risk of mortality ${ }^{10}$. Therefore, it is not surprising that the current study suggests a concomitant worsening in LV systolic and diastolic function and that the presence of LV diastolic dysfunction is independently associated with decline of LV systolic function over time.

Clinical implications. The ability to detect progression in myocardial dysfunction offers the opportunity to start appropriate therapeutic measures at an earlier stage of the disease, to prevent further impairment in cardiac performance. Because myocardial involvement has been suggested as an important factor in treatment-related mortality in patients with SSc undergoing autologous stem cell transplantation ${ }^{38}$, speckle-tracking strain analysis may contribute to better risk stratification and selection for this treatment. Further, identification of potential associates of development of LV systolic dysfunction over time may help physicians identify which patients with SSc would benefit from a closer echocardiographic followup. Currently, it is unclear how frequently patients with SSc should be followed up for screening of cardiac involvement ${ }^{39}$. The specific healthcare program developed in our institution, which includes yearly examinations by the cardiologist including echocardiography, enabled us to robustly assess the changes in cardiac performance over time, irrespective of disease duration or SSc subtype. Although significant progression in LV systolic dysfunction could be detected in almost $20 \%$, up to $80 \%$ showed normal or stable LV systolic function. This suggests that a standard yearly echocardiographic screening in all patients with SSc is redundant. The current study identified proximal muscle weakness, DLCO, and LV diastolic dysfunction as potential measures that can be used in deciding whether to perform a closer echocardiographic followup.

Limitations. Specific analyses to assess microvascular or macrovascular myocardial ischemia were not systematically performed. However, all patients were routinely seen by a cardiologist and underwent ECG and cardiopulmonary exercise testing, which makes significant ischemia unlikely. The population of our study is representative of patients with SSc referred for screening in a specific healthcare program in a tertiary care center, and 92.3\% fulfilled the ACR 2013 criteria. Certain characteristics (e.g., the relatively low mRSS) reflect that the majority of the population consists of patients with longstanding disease. Additionally, the design of this followup study may introduce selection bias, because standard evaluations are not always possible owing to illness or death in the most severely ill patients. However, to evaluate echocardiographic changes over time, this study design was inevitable. Further, changes in (medical) treatment were not taken into account, and potential associations with changes in cardiac function remain unclear. Results of our current study should be confirmed in larger, prospective, multicenter studies with longer followup.

Development and progression of LV systolic dysfunction could be detected using 2-dimensional speckle-tracking strain (GLS) and not by conventional echocardiography. This decrease in GLS was associated with concomitant deterioration of variables reflecting SSc disease activity, indicating that speckle-tracking analysis can detect subclinical myocardial involvement in patients with SSc. As independent associates, decreased DLCO, muscle weakness, and LV diastolic dysfunction at baseline may help identify patients at risk for myocardial involvement and can guide clinical followup.

\section{REFERENCES}

1. Bryan C, Knight C, Black CM, Silman AJ. Prediction of five-year survival following presentation with scleroderma: development of a simple model using three disease factors at first visit. Arthritis Rheum 1999;42:2660-5.

2. Follansbee WP, Miller TR, Curtiss EI, Orie JE, Bernstein RL, Kiernan JM, et al. A controlled clinicopathologic study of myocardial fibrosis in systemic sclerosis (scleroderma). J Rheumatol 1990;17:656-62.

3. Cameli M, Mondillo S, Righini FM, Lisi M, Dokollari A, Lindqvist $\mathrm{P}$, et al. Left ventricular deformation and myocardial fibrosis in patients with advanced heart failure requiring transplantation. J Card Fail 2016;22:901-7.

4. Moreo A, Ambrosio G, De Chiara B, Pu M, Tran T, Mauri F, et al. Influence of myocardial fibrosis on left ventricular diastolic function: noninvasive assessment by cardiac magnetic resonance and echo. Circ Cardiovasc Imaging 2009;2:437-43.

5. Tzelepis GE, Kelekis NL, Plastiras SC, Mitseas P, Economopoulos $\mathrm{N}$, Kampolis C, et al. Pattern and distribution of myocardial fibrosis in systemic sclerosis: a delayed enhanced magnetic resonance imaging study. Arthritis Rheum 2007;56:3827-36.

6. Tyndall AJ, Bannert B, Vonk M, Airò P, Cozzi F, Carreira PE, et al. Causes and risk factors for death in systemic sclerosis: a study from

Personal non-commercial use only. The Journal of Rheumatology Copyright (C) 2019. All rights reserved. 
the EULAR Scleroderma Trials and Research (EUSTAR) database. Ann Rheum Dis 2010;69:1809-15.

7. Elhai M, Meune C, Avouac J, Kahan A, Allanore Y. Trends in mortality in patients with systemic sclerosis over 40 years: a systematic review and meta-analysis of cohort studies. Rheumatology 2012;51:1017-26.

8. Allanore Y, Meune C, Vonk MC, Airo P, Hachulla E, Caramaschi P, et al. Prevalence and factors associated with left ventricular dysfunction in the EULAR Scleroderma Trial and Research group (EUSTAR) database of patients with systemic sclerosis. Ann Rheum Dis 2010;69:218-21.

9. Yiu KH, Schouffoer AA, Marsan NA, Ninaber MK, Stolk J, Vlieland TV, et al. Left ventricular dysfunction assessed by speckle-tracking strain analysis in patients with systemic sclerosis: relationship to functional capacity and ventricular arrhythmias. Arthritis Rheum 2011;63:3969-78.

10. Faludi R, Kolto G, Bartos B, Csima G, Czirjak L, Komocsi A. Five-year follow-up of left ventricular diastolic function in systemic sclerosis patients: determinants of mortality and disease progression. Semin Arthritis Rheum 2014;44:220-7.

11. Schouffoer AA, Ninaber MK, Beaart-van de Voorde LJ, van der Giesen FJ, de Jong Z, Stolk J, et al. Randomized comparison of a multidisciplinary team care program with usual care in patients with systemic sclerosis. Arthritis Care Res 2011;63:909-17.

12. Meijs J, Schouffoer AA, Ajmone Marsan N, Kroft LJ, Stijnen T, Ninaber MK, et al. Therapeutic and diagnostic outcomes of a standardised, comprehensive care pathway for patients with systemic sclerosis. RMD Open 2016;2:e000159.

13. LeRoy EC, Medsger TA Jr. Criteria for the classification of early systemic sclerosis. J Rheumatol 2001;28:1573-6.

14. Pellegrino R, Viegi G, Brusasco V, Crapo RO, Burgos F, Casaburi $\mathrm{R}$, et al. Interpretative strategies for lung function tests. Eur Respir $\mathrm{J}$ 2005;26:948-68.

15. Graham BL, Brusasco V, Burgos F, Cooper BG, Jensen R, Kendrick A, et al. Executive Summary: 2017 ERS/ATS standards for single-breath carbon monoxide uptake in the lung. Eur Respir J 2017;49:16E0016.

16. Hansell DM, Bankier AA, MacMahon H, McLoud TC, Muller NL, Remy J. Fleischner Society: glossary of terms for thoracic imaging. Radiology 2008;246:697-722.

17. Yiu KH, Ninaber MK, Kroft LJ, Schouffoer AA, Stolk J, Scherer $\mathrm{HU}$, et al. Impact of pulmonary fibrosis and elevated pulmonary pressures on right ventricular function in patients with systemic sclerosis. Rheumatology 2016;55:504-12.

18. ATS/ACCP Statement on cardiopulmonary exercise testing. Am J Respir Crit Care Med 2003;167:211-77.

19. Meijs J, Schouffoer AA, Ajmone Marsan N, Stijnen T, Putter H, Ninaber MK, et al. A prediction model for progressive disease in systemic sclerosis. RMD Open 2015;1:e000113.

20. Smedema JP, Snoep G, van Kroonenburgh MP, van Geuns RJ, Dassen WR, Gorgels AP, et al. Evaluation of the accuracy of gadolinium-enhanced cardiovascular magnetic resonance in the diagnosis of cardiac sarcoidosis. J Am Coll Cardiol 2005; 45:1683-90.

21. Vacca A, Meune C, Gordon J, Chung L, Proudman S, Assassi S, et al. Cardiac arrhythmias and conduction defects in systemic sclerosis. Rheumatology 2014;53:1172-7.

22. Lang RM, Badano LP, Mor-Avi V, Afilalo J, Armstrong A, Ernande $\mathrm{L}$, et al. Recommendations for cardiac chamber quantification by echocardiography in adults: an update from the American Society of Echocardiography and the European Association of Cardiovascular Imaging. Eur Heart J Cardiovasc Imaging 2015;16:233-70.

23. Nagueh SF, Smiseth OA, Appleton CP, Byrd BF 3rd, Dokainish H, Edvardsen T, et al. Recommendations for the evaluation of left ventricular diastolic function by echocardiography: an update from the American Society of Echocardiography and the European Association of Cardiovascular Imaging. Eur Heart J Cardiovasc Imaging 2016;17:1321-60.

24. Pyxaras SA, Pinamonti B, Barbati G, Santangelo S, Valentincic M, Cettolo F, et al. Echocardiographic evaluation of systolic and mean pulmonary artery pressure in the follow-up of patients with pulmonary hypertension. Eur J Echocardiogr 2011;12:696-701.

25. Rudski LG, Lai WW, Afilalo J, Hua L, Handschumacher MD, Chandrasekaran K, et al. Guidelines for the echocardiographic assessment of the right heart in adults: a report from the American Society of Echocardiography endorsed by the European Association of Echocardiography, a registered branch of the European Society of Cardiology, and the Canadian Society of Echocardiography. J Am Soc Echocardiogr 2010;23:685-713.

26. Negishi K, Negishi T, Hare JL, Haluska BA, Plana JC, Marwick $\mathrm{TH}$. Independent and incremental value of deformation indices for prediction of trastuzumab-induced cardiotoxicity. J Am Soc Echocardiogr 2013;26:493-8.

27. van den Hoogen F, Khanna D, Fransen J, Johnson SR, Baron M, Tyndall A, et al. 2013 classification criteria for systemic sclerosis: an American College of Rheumatology/European League Against Rheumatism collaborative initiative. Arthritis Rheum 2013; 65:2737-47.

28. de Groote P, Gressin V, Hachulla E, Carpentier P, Guillevin L, Kahan A, et al. Evaluation of cardiac abnormalities by Doppler echocardiography in a large nationwide multicentric cohort of patients with systemic sclerosis. Ann Rheum Dis 2008;67:31-6.

29. Poanta L, Dadu R, Tiboc C, Rednic S, Dumitrascu D. Systolic and diastolic function in patients with systemic sclerosis. Eur J Intern Med 2009;20:378-82.

30. Meier FM, Frommer KW, Dinser R, Walker UA, Czirjak L, Denton $\mathrm{CP}$, et al. Update on the profile of the EUSTAR cohort: an analysis of the EULAR Scleroderma Trials and Research group database. Ann Rheum Dis 2012;71:1355-60.

31. Ranque B1, Bérezné A, Le-Guern V, Pagnoux C, Allanore Y, Launay D, et al. Myopathies related to systemic sclerosis: a case-control study of associated clinical and immunological features. Scand J Rheumatol 2010;39:498-505.

32. Follansbee WP, Zerbe TR, Medsger TA Jr. Cardiac and skeletal muscle disease in systemic sclerosis (scleroderma): a high risk association. Am Heart J 1993;125:194-203.

33. West SG, Killian PJ, Lawless OJ. Association of myositis and myocarditis in progressive systemic sclerosis. Arthritis Rheum 1981;24:662-8.

34. Mimura Y, Ihn H, Jinnin M, Asano Y, Yamane K, Tamaki K. Clinical and laboratory features of scleroderma patients developing skeletal myopathy. Clin Rheumatol 2005;24:99-102.

35. Winstone TA, Assayag D, Wilcox PG, Dunne JV, Hague CJ, Leipsic $\mathrm{J}$, et al. Predictors of mortality and progression in scleroderma-associated interstitial lung disease: a systematic review. Chest 2014;146:422-36.

36. Alkotob ML, Soltani P, Sheatt MA, Katsetos MC, Rothfield N, Hager WD, et al. Reduced exercise capacity and stress-induced pulmonary hypertension in patients with scleroderma. Chest 2006;130:176-81.

37. Schwaiblmair M, Behr J, Fruhmann G. Cardiorespiratory responses to incremental exercise in patients with systemic sclerosis. Chest 1996;110:1520-5.

38. Burt RK, Oliveira MC, Shah SJ. Cardiac assessment before stem cell transplantation for systemic sclerosis. JAMA 2014;312:1803.

39. Kowal-Bielecka O, Landewé R, Avouac J, Chwiesko S, Miniati I, Czirjak L, et al. EULAR recommendations for the treatment of systemic sclerosis: a report from the EULAR Scleroderma Trials and Research group (EUSTAR). Ann Rheum Dis 2009;68:620-8. 
APPENDIX 1. Course of inflammation measures between patients with and without GLS reduction at followup.

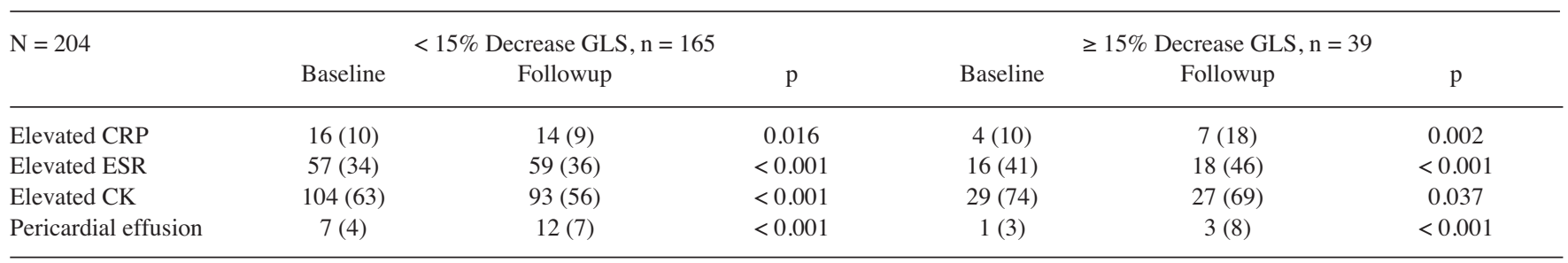

Data are n (\%). CK: creatine kinase; CRP: C-reactive protein; ESR: eythrocyte sedimentation rate; GLS: global longitudinal strain. 